\title{
Dynamic Correlation Research on Grain Markets Based on DCC-GARCH Model
}

\author{
Yan $\mathrm{Ge}^{1, \mathrm{a}}$, Haixia $\mathrm{Wu}^{2, \mathrm{~b}^{*}}$ \\ ${ }^{1}$ School of Public Finance and Tax, Central University of Finance and Economics, Beijing, 100081, \\ China \\ ${ }^{2}$ Internal Business School, Shaanxi Normal University, Xi'an, 710119, China \\ aemail, ${ }^{b}$ email \\ * Corresponding Author: Haixia Wu
}

Keywords: Grain markets, Dynamic correlation, DCC-GARCH model

\begin{abstract}
Based on the week data of the national wheat, corn and soybean wholesale price index from January 9, 1998 to June 22, 2012, the paper inspected the dynamic correlation among the markets of national wheat, corn and soybean using the DCC-GARCH model. The results show that the standardized residual product of the lag stage has a significant influence on the dynamic correlation coefficient. However, the persistence of dynamic correlation among the three markets is not obvious and the correlation coefficient is low. It shows that there is a clear market segmentation phenomenon in China's grain market. Therefore, the profit space of the decentralized investment is still very large, and the price fluctuation is very exogenous.
\end{abstract}

\section{Introduction}

Price fluctuation has been paid close attention due to the dual functions of price discovery and risk transfer. Grain prices, as an important commodity in relation to the people's livelihood and national stability, have been a hot topic in the field of agricultural economy. The frequent fluctuation of grain prices has a great influence on producers, consumers and the macro-economy. Therefore, understanding the characteristics of price fluctuation in grain market has important guiding significance for stabilizing the formulation of grain price policies

In recent years, the grain price fluctuates frequently in our country. As can be seen from Figure 1, from 1999 to 2003, the price of wheat, corn and soybean showed a downward trend in general, but the price of wheat, corn and soybean showed a continuous increase since the fourth quarter of 2003 . The first half of 2008, soybean prices soaring and the emergence of a dozen years of peak, the wholesale market price index reached 246 points, more than doubled in 2007 to 2009 in 2011; corn prices soared from 130 points to 240 points, an increase of 84.61\%. Generally speaking, since 1998, grain price fluctuation in China has been rising and falling at the same time, showing a certain degree of fluctuation correlation between different grain markets.

The correlation analysis of the investment portfolio construction and risk management role in different major grain market, therefore, the quest for reliable estimates of correlation coefficient between grain market has become a hot issue for many researchers (Engle, 2002). But the actual study in order to deal with the problem of convenient, many times the sample constant correlation coefficients to measure the correlation between the market, however, this assumption is often different from the market should be the premise of a time-varying correlation, this view has been confirmed in the financial sector (Gu Yao and Lu Lina, 2006; Dong Xiuliang and Wu Renshui, 2008). Therefore, the quest for reliable estimates of the grain market dynamic relationship one can evaluate the correlation between the grain market and the degree of integration, provide the basis for the formulation of national food policy; on the other hand, investors can cross portfolio allocation, reduce risk and provide an important reference.

At present, the existing literature on the dynamic correlation between the food market is less concerned, most studies still focus on the analysis of the static correlation between the grain market 
and the grain market and related markets. Such as Buguk, Hudson and Hanson (2003) from the supply chain point of view, to study the static correlation between market and catfish of corn and soybean market, the price of corn, soybean market volatility significantly affects the price fluctuation of catfish market. Huang J (2008) believes that the international energy prices and biomass fuel development is to promote the fundamental reason China food prices rise, these factors not only increase the cost of agricultural production, but the growth of the biomass fuel used in the production of crops and the prices of agricultural products. Luo Feng and Niu Baojun (2010) believe that the fluctuation of domestic grain prices is closely related to the price fluctuation of agricultural products and the price lag of their own. Barrera, Mallory, and, Garcia (2011) research on the correlation between American crude oil market and corn market shows that the price fluctuation of crude oil market has significant influence on the price fluctuation of corn market. Luo Feng (2011) thinks that the external demand and the international speculative funds have a strong influence on the prices of agricultural products in China, but the effective exchange rate of RMB has little influence. Kim, and, Doucouliagos (2008) using 1999-2004 years of Japanese wheat, corn and soybean futures market data research, that the three market yield is significantly positive correlation. Zhao and Goodwin (2011) of U.S. corn and soybean option market correlation relationship by using BEKK-GARCH model showed that the corn market price volatility significantly affects the soybean market price fluctuations, but not vice versa.

From the existing literature, literature has on the correlation between grain market and related markets at home and abroad, also discussed the reason of the grain market price fluctuations, but much of the existing research related from the static perspective, the possibility of ignoring the relativity changed with time; at the same time, research on the linkage of the existing literature focused more on the grain market and its related the market, not enough study on correlation between different varieties of grain market, grain production and often has to undertake seasonal, and different grain varieties in the production of shared resources and technology, competition characteristics of land and capital, the study of dynamic relationship between different grain varieties has guiding significance for agricultural production. The DCC-GARCH model because it can well capture the dynamic correlation between financial markets, is widely used in the research on the linkage between financial markets, so this paper will use the DCC-GARCH model to study the dynamic correlation between China's grain market.

\section{Econometric Model and Data Description}

DCC-GARCH Model. The Dynamic Conditional Correlation Multivariate originated from the CCC-GARCH model and CCC-GARCH model, although you can bring advantages to ensure the number of equations is less volatility but the correlation of the model assumptions, the sequence is often not constant with the actual situation, therefore, Engle (2002) DCC-GARCH model is proposed. This model allows the correlation of changes over time, and has obvious computational advantages: on the one hand, the model can be used for large correlation coefficient matrix is estimated, and the model limit the long-term variance covariance matrix for sample variance covariance matrix, thus reducing the number of parameters to be estimated; the number on the other hand, the model of the two step estimation the method to estimate the parameters related in the process of independent related sequences, large correlation matrix for many variables can be easily estimated.

Data Description. The data used in this paper are the national wheat, corn and soybean weekly wholesale market price indices from January 9, 1998 to June 22, 2012. The study of dynamic correlation between the main reason is that most of the grain market of grain crops in the market tend to share information, the demand elasticity of substitution is small, but in the production of inputs such as land and labor have mutual competition, these characteristics theory will lead to effect a change in the market in other markets is significant. Due to the lack of statistical data, part of the reference approach, this paper will not overlap several markets for several weeks to delete the data statistics, a total of 740 sample data, data from the National Bureau of Statistics website economic database and flush industry. 
Table 1. Basic Statistics of week return ratio of wheat, corn and soybeans

\begin{tabular}{cccccc}
\hline & average & $\begin{array}{l}\text { Standard } \\
\text { deviation }\end{array}$ & Skewness & kurtosis & \multicolumn{1}{l}{$\begin{array}{l}\text { JB Normality } \\
\text { test }\end{array}$} \\
\hline$r_{1}$ & 0.0005 & 0.0127 & 0.7830 & 12.1321 & $2643.4100^{* * *}$ \\
$r_{2}$ & 0.0008 & 0.0139 & 0.2854 & 5.8003 & $251.4876^{* * *}$ \\
$r_{3}$ & 0.0004 & 0.0342 & -0.9484 & 17.3907 & $6487.5120^{* * *}$ \\
\hline
\end{tabular}

Note: ***、**、* respectively represent the significance under the level of $1 \%, 5 \%$ and $10 \%$

Table 1 shows that the standard deviation of the price yield of wheat, corn and soybean during the sample period was $0.0127,0.0139$ and 0.0342 respectively, indicating that the volatility of soybean price return is obviously greater than that of the wheat market and the corn market. Comparison of distribution of skewness and kurtosis of 0 and 3, table 1 statistical results showed that the soybean price yield was significantly skewed to the left, and the price of wheat yield, the price of corn yield was significantly skewed to the right; at the same time, wheat, corn and soybean prices return kurtosis are greater than 3, the amount of JB is highly significant in statistics the $1 \%$ level, indicating that the three price return series of Yu Zheng normal distribution, has peak thick tail characteristics, so we will use the leptokurtic distribution to describe the characteristics of the three sequence.

\section{Empirical Analysis}

Basic Test of Price Return of Grain Market. In order to avoid spurious regression, it is necessary to test the stationarity of each sequence. For wheat, corn, soybean yield, price, ${ }_{1}, r_{2}$ and $r_{3}$ of unit root test. Select the lag order of 0, no intercept and trend, ADF and PP statistical test results show that: at the $1 \%$ significant level, the price return series, and reject the unit root hypothesis, that is, $r_{1}, r_{2}$ and $r_{3}$, stationary time series, and so on, there's no false regression modeling.

The sequence of wheat, corn, soybean prices return autocorrelation and partial autocorrelation test, we found that the price of wheat yield and the soybean price rate of return and the 1 and 6 order lag correlation value is strong; the price of corn yield with 1, 3 and 4 order lag value relevance is strong. Therefore, the average equation of the price return of the three cities adopts the following form:

$$
\begin{gathered}
r_{1, t}=\alpha r_{1, t-1}+\beta r_{1, t-6}+\varepsilon_{1, t} \\
r_{2, t}=\alpha r_{2, t-1}+\beta r_{2, t-3}+\gamma r_{2, t-4}+\varepsilon_{2, t} \\
r_{3, t}=\alpha r_{3, t-1}+\beta r_{3, t-6}+\varepsilon_{3, t}
\end{gathered}
$$

The regression results of the above mean equation show that all the coefficients of variables are tested by significance test.

In this paper, the autocorrelation test of the square of the residual sequence is used to test whether the time series has heteroscedasticity. The mean equation of the three market price yield obtained by the above process can obtain the residual sequence and the square of the residual sequence, and do the autocorrelation test with the lag of the Ljing-Box Q statistic and the 12 order pair. The results show that there is no significant autocorrelation between the residuals of the three market yield and the autocorrelation of the residual squares. On the sequence of sequence diagram, as shown in Figure 2, we can see that the fluctuation of residual square wheat, corn and soybean market has obvious time-varying and clustering, the corn market and the soybean market is the most obvious manifestation, namely three market volatility fluctuates behind the big heels behind the small fluctuations, fluctuation with small fluctuation. Therefore, it can be concluded that the three market price yield has significant heteroscedasticity, that is, the ARCH effect. 

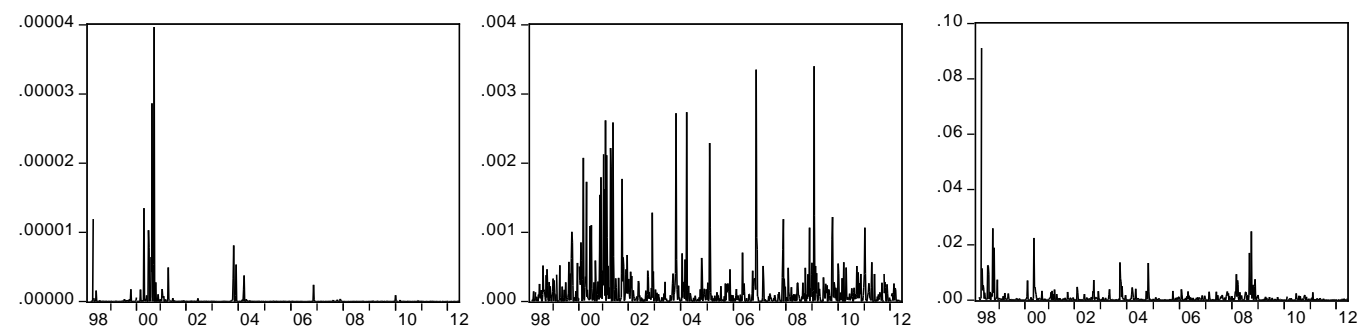

Figure 2. Sequence diagram of $\varepsilon_{t}^{2}$ of wheat, corn, soybeans

Estimation Result Based on DDC-GARCH. Bollerslev GARCH $(1,1)$ model can fit the time series volatility well, taking into account the simplicity of the model, this paper uses the GARCH $(1,1)$ model to analyze the volatility of the three market price earnings ratio. Table 2 of the single variable GARCH $(1,1)$ to establish the residual sequence model and square sequence Ljing-BoxQ statistic test showed that the residual sequence does not exist autocorrelation and heteroscedasticity, illustrate the mean equation and the variance equation model set is reasonable.

Table 1. GARCH parameter estimates and DCC coefficient estimates for each market price return

\begin{tabular}{lllllll}
\hline & Constant(M) & AR(1) & Constant(V) & $\alpha$ & $\beta$ & $\alpha+\beta$ \\
\hline Wheat & 0.0003 & $-0.1335^{* * *}$ & $0.0487^{* * *}$ & $0.3018^{* * *}$ & $0.7000^{* * *}$ & 1.0018 \\
market & & & & & \\
& $(1.141)$ & $(-2.630)$ & $(2.596)$ & $(3.876)$ & $(12.140)$ & \\
Corn & $0.0013^{* * *}$ & $-0.1176^{* *}$ & $0.1456^{* *}$ & $0.2320^{* * *}$ & $0.7095^{* * *}$ & 0.9415
\end{tabular}

market

$\begin{array}{lllllll} & (2.976) & (-2.252) & (2.053) & (3.885) & (9.697) & \\ \text { Soybeans } & 0.0002 & -0.2463^{* * *} & 0.4496 & 0.1848^{* * *} & 0.7908^{* * *} & 0.9756\end{array}$

market

$$
(-4.192)
$$

$\operatorname{DCC}(1,1)$

$$
0.0856^{* * *} \quad 0.3610^{* * *}
$$

(2.766)

Note: $* * *$ 、** $*$ respectively represent the significance under the level of $1 \%, 5 \%$ and $10 \%$. The mean equation adopts the form of ARMA $(1,0)$; the Constant $(M)$ is the constant of the mean equation, and the Constant (V) is the constant of the variance equation.

In order to more directly reflect the dynamic changes of market conditions of soybean wheat and maize, the correlation coefficient between the difference and the constant correlation coefficients are given in Figure 3, figure three path between the market dynamic correlation coefficient with the change of time, in which each line graph for constant correlation coefficients. See the following features from Figure 3 we can: first, ordinary wheat market correlation coefficient is 0.2044 , the correlation coefficient is greater than the mean dynamic conditional correlation coefficient of 0.1617; but the constant correlation coefficients of maize market and the soybean market were 0.0712 and 0.0617, the correlation coefficient is less than the dynamic correlation coefficient of the respective mean $0.1684,0.1175$, which indicates that the difference of constant correlation coefficients and dynamic correlation coefficients significantly. Second, during the whole sample period, the dynamic correlation coefficients of wheat market, corn market and soybean market showed stronger temporal variation characteristics, and the instantaneous change characteristics were significant. Third, the dynamic conditions of the grain market correlation coefficient are an important index to measure the 
degree of convergence of grain market operation, dynamic conditional correlation coefficient shows that high grain market price trend of convergence degree, high degree of market integration; conversely, the food market in the trend of a larger deviation, market segmentation. But overall, during the entire sample period dynamic correlation coefficient of variation between the three markets is very similar to the dynamic coefficient of the wheat market and the soybean market volatility, but the correlation between the dynamic correlation coefficient of the three markets is not high, this shows that China's grain market segmentation feature is very obvious.

Table 3. Grain market; dynamic condition; correlation coefficient; basic statistical analysis

\begin{tabular}{lllll}
\hline & Mean & Maximum & Minimum & $\begin{array}{c}\text { Standard } \\
\text { deviation }\end{array}$ \\
\hline $\operatorname{Corr}\left(r_{1}, r_{2}\right)$ & 0.1617 & 0.6384 & -0.3659 & 0.0840 \\
$\operatorname{Corr}\left(r_{1}, r_{3}\right)$ & 0.1684 & 0.8023 & -0.2841 & 0.0843 \\
$\operatorname{Corr}\left(r_{2}, r_{3}\right)$ & 0.1175 & 0.4874 & -0.3634 & 0.0797 \\
\hline
\end{tabular}

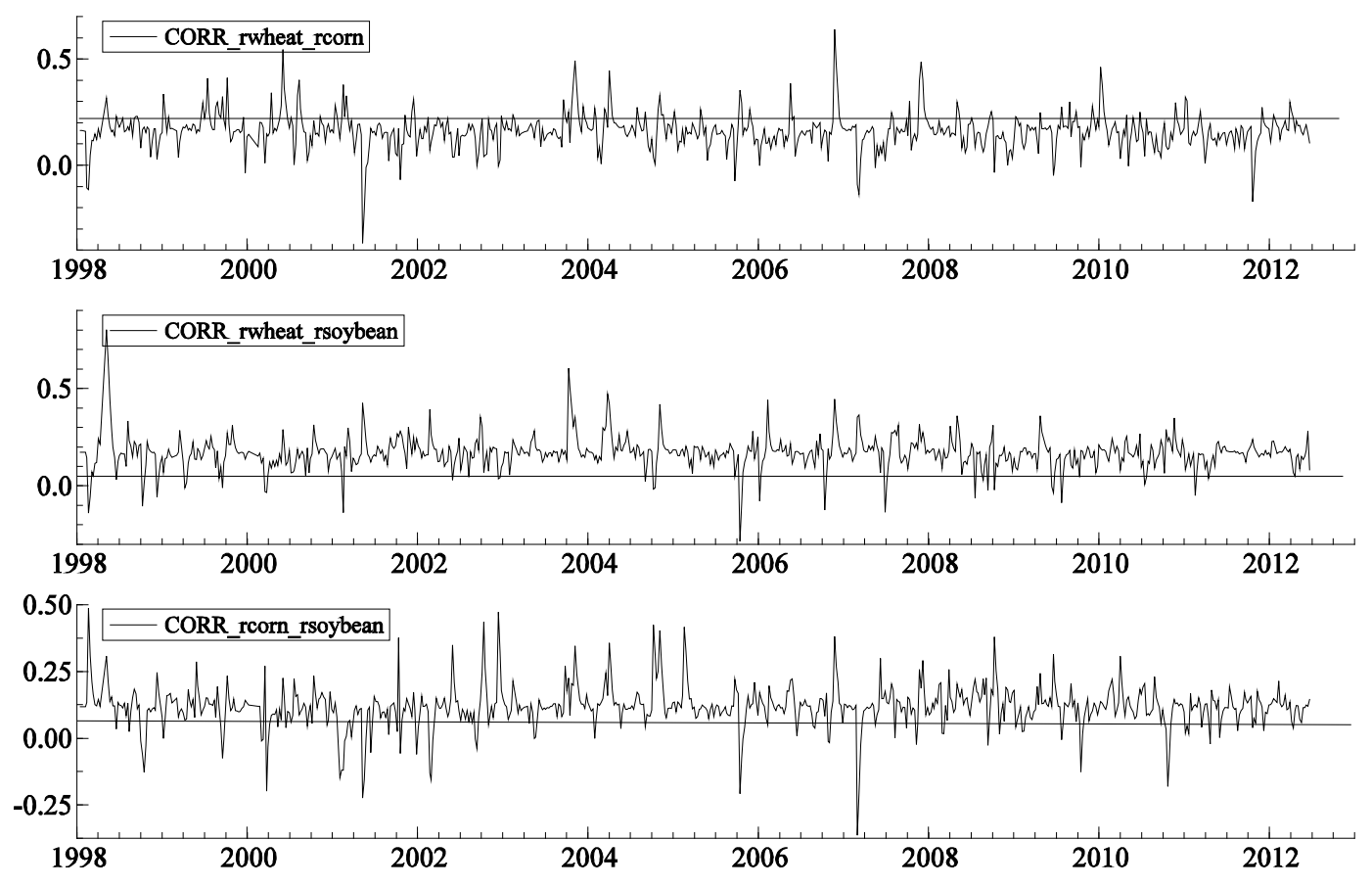

Fiugre 3. Coefficient of correlation and dynamic correlation coefficient of wheat, maize and soybean from 1998 to 2012

\section{Conclusions and Policy Recommendations}

The paper take the national wheat, corn and soybean wholesale price index of the weekly data as samples, using the DCC-GARCH model of China's wheat, corn and soybean markets between the dynamic correlations were investigated. The results show that the effect of lag of standardized residual product of a period of dynamic correlation coefficient is significant, but the persistence of wheat, corn, soybean market correlation between is not obvious; the correlation coefficient of total wheat, maize and soybean in China between the three markets is positive, and in the time path show obvious time variable characteristics; in comparison, the dynamic conditions of wheat and corn market, soybean market is greater than the correlation coefficient between the dynamic conditions of maize market and the soybean market correlation coefficient, but the dynamic correlation coefficient between the three markets are relatively low, that China's grain market segmentation phenomenon is more obvious. Therefore, for investors, diversification of investment returns on the grain market 
space is still great; for policy makers, to further deepen the food market open policy is the only way which must be passed to ease food market segmentation.

\section{Acknowledgements}

The paper is the periodical result of the Youth Fund Project of National Natural Science Foundation named "Research on Transmission Mechanism of Financial Factors on Price Fluctuation of Cotton and the Forecast Effect from the Perspective of Grains Financialisation" (Grant No. 71603153), Key Project of Social Science Foundation of Shaanxi named "Research on Innovation Models of Value Integration and Increment of Industrial Chain of Cotton in Shaanxi under the Background of Supply-Side Reform” (Grant No. 2016D003) and the Special Fund Project of Fundamental Research Funds for the Central Universities in Shaanxi Normal University named "Asymmetrical Response of Gasoline Price on Crude Price Fluctuation for Short term and long term”(Grant No. 15SZYB18). It is also supported by Institute of Rural Reform and Economic and Social Development of Anhui University.

\section{References}

[1] Gu Yao, Lu Lina. Information Spillover Effects between HU, SHEN, GANG Stock Markets and Dynamic Conditional Correlation [J]. The Journal of Quantitative \& Technical Economics, 2006(8): 142-151.

[2] ENGLE R F, Dynamic conditional correlation: A simple class of multivariate generalized autoregressive conditional heteroskedasticity models [J]. Journal of Business and Economic Statistics, 2002(2): 339-350.

[3] BUGUK C, HUDSON D, HANSON T. Price volatility spillover in agricultural markets: an examination of U.S. catfish markets [J]. Journal of Agricultural and Resource Economics, 2003(28): 86-99.

[4] Luo Feng, Niu Baojun. An Empirical Research on the Influential Factors of China's Grain Prices Fluctuation [J]. Journal of South China Agricultural University (Social Science Edition), 2010(9): 51-58.

[5] BARRERA T A, MALLORY M, GARCIA P. Volatility spillovers in the U.S. crude oil, corn, and ethanol markets [J]. Paper presented at the NCCC-134 Conference on Applied Commodity Price Analysis, Forecasting, and Market Risk Management St. Louis, Missouri, April 18-19, 2011. [6] KIM J. DOUCOULIAGOS H. Realized volatility and correlation in grain futures markets: testing for spillover effects [J]. Review of Futures Markets, 2008(17): 275-300.

[7] ZHAO J, GOODWIN B K. Volatility spillover in agricultural commodity markets: an application involving implied volatilities from options markets [J]. Selected Paper prepared for presentation at the Agricultural \& Applied Association's 2011 AAEA \& NAREA Joint Annual Meeting, Pittsburgh, Pennsylvania, July 24-26, 2011

[8] HAMAO Y, MASULIS R W, VICTOR N G. Correlations in price changes and volatility across international stock markets [J]. The Review of Financial Studies, 1990(3): 281-307. 